\title{
Bladder Instability and Stress Incontinence
}

\author{
Edward McGuire
}

\section{Department of Urology, University of Michigan, Ann Arbor}

\begin{abstract}
The relationship between bladder instability and stress incontinence is complex, but the two conditions frequently coexist; when they do, the unstable bladder appears to be etiologically related to the stress incontinence, since surgical repair of the latter resolves symptomatic bladder instability in about $80 \%$ of such patients.
\end{abstract}

Key words: detrusor instability, stress incontinence, urge incontinence, motor urge incontinence, sensory urge incontinence

\section{INTRODUCTION}

Bladder instability refers to a condition characterized by sudden bladder contractility during a cystometrogram. In other words, it is a bladder contraction which occurs without its owner's permission. The condition was described by Bates, but was also described by Hodgekinson, who termed the condition "dyssynergic detrusor dysfunction" [Bates et al., 1970; Hodgekinson et al., 1963]. The unstable bladder, however, is the most commonly used term, since urodynamic terminology now restricts dyssynergia to a description of antagonistic activity, generated reflexively between the bladder and the urethral sphincter [ICS, 1980].

The International Continence Society, using data and concepts developed over several years, has defined bladder instability in urodynamic terms [ICS, 1980]. An unstable bladder contracts involuntarily during the filling phase of a cystometrogram. Initially, a $15-\mathrm{cm}$ water pressure increase was required before the diagnosis could be made, but that requirement was later eliminated, since some unstable contractions did not develop a $15-\mathrm{cm} / \mathrm{H}_{2} \mathrm{O}$ pressure elevation during filling. Conversely, the Urodynamic Society defined a stable bladder as one that did not contract during the filling phase of a cystometrogram, despite provocation. It is important to recognize that these definitions are urodynamic definitions only, and as such are not the same as "urge incontinence," which is a term used to describe the historical detail related by a patient who says she cannot always reach the toilet in time. While many American and Canadian workers use the International Continence Society (ICS) terminology which has been published in the British and American literature, there are a number of other terms used to describe an involuntary bladder contraction including detrusor hyperreflexia, spastic bladder, uninhibited bladder, and even hypertonic bladder.

Received for publication April 4, 1988; accepted July 18, 1988.

Address reprint requests to Dr. Edward McGuire, University of Michigan, 1500 E. Medical Center Drive, Urology Box 3003, Ann Arbor, MI 48109. 
This profusion of terminology, which is in many instances tied to concepts about pathophysiology, has resulted in an apparent disagreement regarding the significance of detrusor instability in patients with stress incontinence. That disagreement can be summarized as follows: detrusor instability is the most common reason for failure of stress-incontinence operations, because it is not identified preoperatively [Cardozo and Stanton, 1980; Arnold et al., 1973]; alternatively, detrusor instability is unrelated to the success or failure of stress-incontinence operations in the majority of patients, provided one can objectively identify stress incontinence prior to operation [McGuire and Savastano, 1985; McGuire et al., 1976].

\section{RESULTS OF OPERATION}

Cardozo and co-workers reported operative results for stress-incontinence surgery in 1979 on 92 patients, none of whom had an unstable detrusor by strict urodynamic criteria [Cardozo et al., 1979]. Postoperatively, 18.5\% had urodynamically demonstrable detrusor instability. All of these women had radiographically and urodynamically demonstrated stress incontinence. Despite the negative urodynamic testing pre-operatively, however, 50 of the 92 women complained of urge incontinence. Postoperatively, 31 of these women still complained of urge incontinence, and 17 had definite detrusor instability by urodynamic criteria.

In another study of 582 women with stress incontinence, 172 had detrusor instability either by urodynamic testing (142) or only a history of urge incontinence (30) [McGuire and Savastano, 1985]. Of the group with pre-operative urge incontinence, 56 (or $31 \%$ ) continued to have urge incontinence postoperatively, and an additional 24 (or $5.8 \%$ ) of those without pre-operative urge incontinence developed that condition postoperatively. Of the entire group then, $30 \%$ had urge incontinence pre-operatively, but at 6 months, only $3.9 \%$ still had symptomatic urge incontinence, and $3.1 \%$ persistent or recurrent stress incontinence. Together then, $7 \%$ of patients failed to respond to the operation, about half as a result of bladder instability and half as a result of stress incontinence.

Comparison of these results with the Cardozo series suggests that terminology is the problem rather than any real difference in outcome. There were 92 patients with SUI, 50 of whom had "urge incontinence." Postoperatively, 22 had urge incontinence, or $24 \%$ of the total, and $38 \%$ of those with pre-operative urge incontinence. Of the 17 patients with urodynamically demonstrated detrusor instability postoperatively, only 8 had symptomatic urge incontinence. Since the development of urge incontinence in women without that symptom pre-operatively occurs in about $6 \%$, some of those in the Cardozo series must have developed urge incontinence only postoperatively.

Both studies demonstrated that "urge incontinence' is common in women with documented stress incontinence, and both show a beneficial effect of surgery on the symptom of "urge incontinence," and paradoxically both studies show that some patients will develop both urge incontinence and identifiable detrusor instability postoperatively. In the Cardozo series, moreover, 16 patients still had symptoms and objective findings of stress incontinence postoperatively. Since these patients can be expected also to have a high incidence of symptomatic urge incontinence, it is not clear that the basic outcome in these two series is different. 


\section{DISCUSSION}

The problem here seems to be one of definition. There is no problem with defining detrusor instability in urodynamic terms, as long as it is recognized that this definition has no real clinical meaning. That, unfortunately, is not the case, and the ICS has suggested that "urge incontinence" be divided into two categories: motor urge, in which the incontinence is shown to be related to a detrusor contraction by cystometry, and sensory urge, where the cystometry does not show a detrusor contraction [ICS, 1980]. The ICS goes on to state then that "sensory urgency incontinence" is incontinence which is "not caused by a detrusor contraction." That simply is not proven and not provable. Patients who are incontinent, with urge incontinence, with a negative cystometrogram cannot be said to be incontinent as a result of some process other than a detrusor contraction, on that basis alone. Indeed, the results of continuous monitoring of intravesical pressure, in patients with urge incontinence, but a normal provocative cystometrogram, demonstrate that a detrusor contraction is almost invariably the cause of their "urge incontinence" [Bradley et al., 1982].

In addition, there is now substantial evidence that detrusor instability which occurs during the course of a cystometrogram may be entirely asymptomatic. Thus, the cystometric study is plagued by false-negative and false-positive results, and it cannot be used as a definitive test of anything except bladder compliance. There is no information which relates the ease of provocation of an unstable detrusor response in women with stress incontinence to the eventual outcome of a surgical procedure to treat the stress incontinence [McGuire and Savastano, 1985]. Patients with overt detrusor instability do as well postoperatively as those in the Cardozo series with normal cystometrograms.

At present, it seems prudent to accept a history of urge incontinence as probably indicative of a problem with detrusor control. Women with symptoms of stress incontinence should be objectively demonstrated to have that condition prior to operation. The objective of the procedure is to cure the stress incontinence, and since that can be achieved about $90 \%$ of the time, there is no good reason not to proceed with an operation if the patient agrees. Patients with urge incontinence will not do quite as well overall as those without urge incontinence, but there is no certain way using current urodynamic techniques to determine what the outcome will be. A routine cystometrogram used to make the diagnosis of detrusor instability is a blunt instrument: if negative, it does not rule out the condition; if positive, it does not mean stress incontinence is not also present, nor does it necessarily suggest a bad operative result.

In contrast, women with urge incontinence, but without objectively demonstrable stress incontinence, do poorly with any operation. These findings suggest that the primary diagnostic effort should be directed toward the accurate clinical and radiographic identification of true stress incontinence rather than the cystometric determination of detrusor instability.

The problem of sudden bladder contractility, which is difficult to control, is much more complicated than it might appear. Resnik and co-workers reported that urge incontinence was the most common symptom in a very large group of elderly patients [Resnick and Scherr, 1984]. Urodynamic evaluation, however, often fails to correlate with these symptoms, in that sphincter weakness is a more common finding 
than overt detrusor instability on a laboratory evaluation which includes a cystometrogram [Bennett et al., 1984]. In those patients with easily demonstrable detrusor instability-for example, after spinal cord injury-a definite response to anticholinergic agents almost always occurs [McGuire and Savastano, 1983]. Children with nocturnal eneuresis on the other hand respond less well to anticholinergic medications, despite the fact that sleep cystometrograms demonstrate that an uninhibited detrusor response constitutes the basic abnormality [Khan et al., 1984; Norgaard et al., 1984]. These children often show perfectly normal urodynamic studies when the tests are performed on an awake, alert child. These findings suggest that overt detrusor instability related to a neurologic cause can be described as bladder hyperreflexia, while the more common "urge incontinence" is a problem of control of a basically normal bladder. Since the cystometrogram reinforces sensory input, it obviates at least one of the factors involved in control of detrusor function, that of poor cerebral appreciation of the degree of vesical filling [McGuire and Savastano, 1984; Motzkin, 1968; Maggi and Meli, 1986]. This condition, described by Yeates [1972] as "hypesthetic urgency,"' is common, and the standard urodynamic test for uninhibited bladder activity, the cystometrogram, paradoxically helps the patient compensate for this disability. Efforts to treat these patients involve the bladder drill in England, and timed voiding in the United States often in conjunction with anticholinergic agents, because these techniques incorporate methods which obviate sudden reflex activity precipitated by volume which occurs without any warning. This kind of detrusor contractile control problem is not a primary bladder problem, and perhaps should not even be called an unstable detrusor, since that implies that the bladder is easily excited. It seems, rather, to be related to apparent cerebral disinterest in bladder events. However, the clinical problem is urinary incontinence, for which difficulty, therapy is usually directed at the bladder.

Sutherst and co-workers reported that perfusion of the urethra with fluid did not, in the patients studied, induce a detrusor contraction [Sutherst and Brown, 1978]. That report has been accepted as conclusive evidence that stress incontinence does not cause detrusor instability. Despite that evidence, there clearly is a relationship between the condition of stress incontinence and detrusor instability. Unfortunately, the cystometrogram, even with rectal subtraction pressures, does not help to resolve the central problem, which remains in a woman with both stress and urge incontinence if an operation is indicated; and if so, can we predict what will happen postoperatively to the "urge incontinence"? The answer is we can't, but the incidence of persistent instability is low, nearly the same as the de novo appearance of that problem in women with stress incontinence subjected to operation, with no antecedent history which suggests a problem with detrusor control.

\section{REFERENCES}

Arnold EP, Webster R Jr, Loose H, Brown ADG, Turner-Warwick RT, Whiteside CG, Jequier AM (1973): Urodynamics of female incontinence: Factors influencing the results of surgery. Am J Obstet Gynecol 117:305.

Bates CP, Whiteside CG, Turner-Warwick RT (1970): Synchronous cine/pressure/flow/cystourethrography with special reference to stress and urge incontinence. $\mathrm{Br} \mathrm{J}$ Urol 42:714.

Bennett CJ, Wells T, Diokno AC, Brink C (1984): Urinary incontinence in elderly female patients. "Proceedings of the International Continence Society, Innsbruck, 1984." pp 76-77.

Bradley WE, Bhatia N, Haldenian S (1982): Twenty-four hour continuous monitoring. "Proceedings of the American Urological Association, 1982," Abstract 113. 
Cardozo C, Stanton SL (1980): Genuine stress incontinence and detrusor instability: A clinical and urodynamic review of 200 cases. Br J Obstet Gynecol 87:184.

Cardozo LD, Stanton SC, Williams JE (1979): Detrusor instability following surgery for genuine stress incontinence. Br J Urol 51:204.

Hodgekinson CP, Ayers MA, Drukker BH (1963): Dyssynergic detrusor dysfunction in the apparently normal female. Am J Obstet Gynecol 87:717.

International Continence Society (1980): Third report on the standardization of terminology of lower urinary tract function. Br J Urol 52:348.

Khan Z, Meiza M, Leiter E (1984): Role of detrusor hyperreflexia (bladder instability) in primary eneuresis. "Proceedings of the International Continence Society, Innsbruck, 1984." pp 107-108.

Maggi CA, Meli A (1986): Do "conscious" and "reflex" micturition have a separate sensory input: Implications for clinical urodynamics. Neurourol Urodyn 5:563.

McGuire EJ, Lytton B, Pepe V, Kohorn EI (1976): Stress urinary incontinence. Obstet Gynecol 47:255.

McGuire EJ, Savastano JA (1983): Long-term follow-up of spinal cord injury patients managed by intermittent catheterization. J Urol 129:775

McGuire EJ, Savastano JA (1984): Urodynamic studies in eneuresis area the non neurogenic bladder. J Urol 132:299.

McGuire EJ, Savastano JA (1985): Stress incontinence and detrusor instability/urge incontinence. Neurourol Urodyn 4:313.

Motzkin D (1968): The significance of deficient bladder sensation. J Urol 100:445.

Norgaard JP, Knudsen N, Hansen JH, Neilsen JB, Djurhuus JC (1984): Overnight monitoring of children with nocturnal eneuresis. "Proceedings of the International Continence Society, Innsbruck, 1984." pp 105-106.

Resnick NM, Scherr P (1984): Urinary incontinence in the community-dwelling elderly. "Proceedings of the International Continence Society, Innsbruck, 1984." pp 70-71.

Sutherst JR, Brown M (1978): The effect on the bladder pressure of sudden entry of fluid into the posterior urethra. Br J Urol 50:400.

Yeates WK (1972): Disorders of bladder function. Am R Coll Surg 50:335. 